\title{
Does septal myectomy reduce risk of sudden cardiac death in patients with hypertrophic cardiomyopathy?
}

\author{
Hartzell V. Schaff, MD, and Anita Nguyen, MBBS
}

\author{
From the Department of Cardiovascular Surgery, Mayo Clinic, Rochester, Minn. \\ This work was supported by the Paul and Ruby Tsai Family. \\ Disclosures: Authors have nothing to disclose with regard to commercial support. \\ Received for publication April 16, 2018; accepted for publication April 17, 2018; available ahead of print May 12, \\ 2018. \\ Address for reprints: Hartzell V. Schaff, MD, Mayo Clinic, 200 First St SW, Rochester, MN 55905 (E-mail: \\ schaff@mayo.edu). \\ J Thorac Cardiovasc Surg 2018;156:748-9 \\ $0022-5223 / \$ 36.00$ \\ Copyright $(2) 2018$ by The American Association for Thoracic Surgery \\ https://doi.org/10.1016/j.jtcvs.2018.04.082
}

Arguably, the 2 most important developments in the clinical management of patients with hypertrophic cardiomyopathy (HCM) are the understanding that left ventricular outflow tract (LVOT) obstruction is present in $60 \%$ to $70 \%$ of symptomatic patients and that implantable cardioverter defibrillators (ICDs) can dramatically reduce risk of sudden cardiac death (SCD) in appropriately selected patients. ${ }^{1-3}$ The challenge in preventing SCD is identification of patients at increased risk of fatal arrhythmias to justify the cost and potential morbidity of device implantation. . $^{3,4}$ Although there is some evidence that LVOT obstruction may be a risk factor for $\mathrm{SCD}^{5,6}$ this is not universally accepted, and the 2011 American Heart Association/ American College of Cardiology guidelines state only that marked LVOT obstruction might be a potential SCD risk modifier when estimated risk remains borderline after documentation of conventional predictive factors. ${ }^{7}$ In contrast, the European Society of Cardiology (ESC) guidelines list LVOT obstruction as a major clinical feature associated with SCD and include LVOT gradient in their risk model. ${ }^{8}$ An important issue, then, is whether relief of LVOT obstruction by septal myectomy alters risk assessment of SCD.

In this issue of the Journal, Desai and colleagues 9 describe the risk of SCD in their cohort of 1809 patients with obstructive HCM and compare the observed adverse event rates with those predicted by 2 different risk models. Sixty-four percent of patients underwent septal myectomy. They observed little correlation between calculated risk scores and actual rates of SCD. In the group of patients predicted to have highest risk $(9 \%)$ of SCD or ICD discharge, the 5-year event rate was $4.8 \%$. Indeed, adverse event rates were similar among the 3 ESC risk categories, and after 5 years of follow-up, approximately two-thirds of events occurred in patients classified as low risk by the ESC risk calculator. Standard risk assessment following the American Heart Association/American College of Cardiology guidelines also had poor predictive value, because

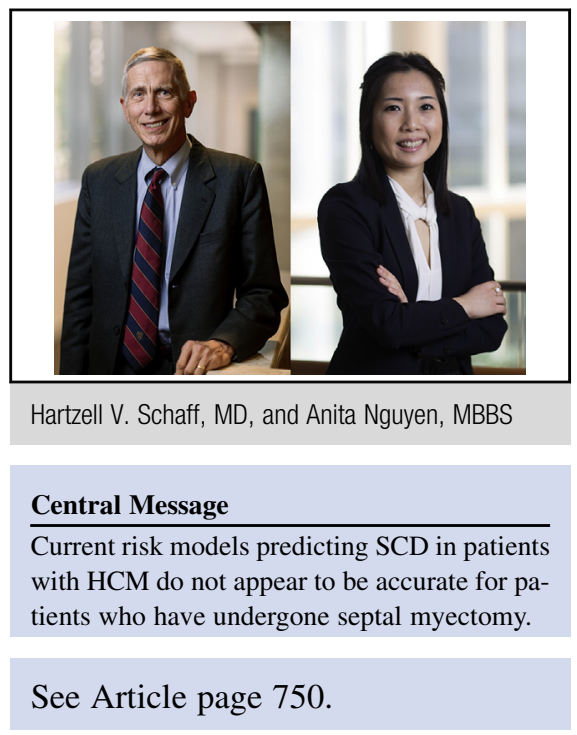

$65 \%$ of events after 5 years occurred in patients with no risk factors.

The study suggests that SCD risk may be modified by septal myectomy in patients with obstructive HCM and that different models might be required for postoperative patients. Previous studies support this. Ommen and colleagues ${ }^{5}$ reported that survival of patients after septal myectomy was superior to survival of unoperated patients, and this improved outcome was due, in part, to greater freedom from SCD. In an investigation of patients with HCM and ICD implants, McLeod and associates ${ }^{6}$ reported an annualized event rate of $0.24 \%$ per year after myectomy compared with $4.3 \%$ per year in a nonmyectomy group.

Thus, it is not surprising that risk models developed for a heterogeneous population of patients with HCM might not apply to patients after myectomy, and there are multiple possible explanations for this. The ESC risk calculator includes LVOT gradient, left atrial size, and maximal left ventricular (LV) wall thickness in addition to other clinical variables. The risk score calculated for a patient with obstruction would be expected to change after relief of LVOT gradient. Further, follow-up of patients after myectomy confirms that gradient relief is associated with both reduction in left atrial dimension and LV mass. ${ }^{10-12}$ Thus, calculated risk of SCD for an individual patient would be expected to change after septal myectomy.

The finding of imprecision in risk assessment in patients who have had successful septal myectomy should not detract from the importance of prevention of SCD in 
patients with HCM after gradient relief. ${ }^{13}$ There is clear consensus on the use of ICDs in patients for secondary prevention after cardiac arrest or documented ventricular tachycardia. The potential survival benefit of devices should be discussed with patients who have family members with HCM who died suddenly, those with unexplained syncope, and patients with exercise-induced hypotension or massive LV hypertrophy ( $\mathrm{LV}$ wall thickness $>30 \mathrm{~mm}$ ). Older patients ( $>60$ years) may have lower risk of SCD than younger patients. It is important also to recall that timing of SCD in patients with HCM is highly unpredictable, and freedom from device discharge during the first 5 years after implantation does not guarantee that rescue by the ICD will not be necessary during the subsequent 5 to 10 years.

\section{References}

1. Maron MS, Olivotto I, Zenovich AG, Link MS, Pandian NG, Kuvin JT, et al. Hypertrophic cardiomyopathy is predominantly a disease of left ventricular outflow tract obstruction. Circulation. 2006;114:2232-9.

2. Maron BJ, Shen WK, Link MS, Epstein AE, Almquist AK, Daubert JP, et al. Efficacy of implantable cardioverter-defibrillators for the prevention of sudden death in patients with hypertrophic cardiomyopathy. N Engl J Med. 2000;342: 365-73.

3. Maron BJ, Casey SA, Olivotto I, Sherrid MV, Semsarian C, Autore C, et al. Clinical course and quality of life in high-risk patients with hypertrophic cardiomyopathy and implantable cardioverter-defibrillators. Circ Arrhythm Electrophysiol. 2018;11:e05820.

4. Lin G, Nishimura RA, Gersh BJ, Phil D, Ommen SR, Ackerman MJ, et al. Device complications and inappropriate implantable cardioverter defibrillator shocks in patients with hypertrophic cardiomyopathy. Heart. 2009;95:709-14.
5. Ommen SR, Maron BJ, Olivotto I, Maron MS, Cecchi F, Betocchi S, et al. Long-term effects of surgical septal myectomy on survival in patients with obstructive hypertrophic cardiomyopathy. J Am Coll Cardiol. 2005;46:470-6.

6. McLeod CJ, Ommen SR, Ackerman MJ, Weivoda PL, Shen WK, Dearani JA, et al. Surgical septal myectomy decreases the risk for appropriate implantable cardioverter defibrillator discharge in obstructive hypertrophic cardiomyopathy. Eur Heart J. 2007;28:2583-8.

7. Gersh BJ, Maron BJ, Bonow RO, Dearani JA, Fifer MA, Link MS, et al 2011 ACCF/AHA guideline for the diagnosis and treatment of hypertrophic cardiomyopathy: a report of the American College of Cardiology Foundation/ American Heart Association task force on practice guidelines. Developed in collaboration with the American Association for Thoracic Surgery, American Society of Echocardiography, American Society of Nuclear Cardiology, Heart Failure Society of America, Heart Rhythm Society, Society for Cardiovascular Angiography and Interventions, and Society of Thoracic Surgeons. J Am Coll Cardiol. 2011;58:e212-60.

8. Elliott PM, Anastasakis A, Borger MA, Borggrefe M, Cecchi F, Charron P, et al. 2014 ESC guidelines on diagnosis and management of hypertrophic cardiomyopathy: the task force for the diagnosis and management of hypertrophic cardiomyopathy of the European Society of Cardiology (ESC). Eur Heart J. 2014;35:2733-79.

9. Desai MY, Smedira NG, Dhillon A, Masri A, Wazni O, Kanj M, et al. Prediction of sudden death risk in obstructive hypertrophic cardiomyopathy: potential for refinement of current criteria. J Thorac Cardiovasc Surg. 2018;156:750-9.

10. Nguyen A, Schaff HV, Nishimura RA, Dearani JA, Geske JB, Lahr BD, et al Determinants of reverse remodeling of the left atrium following transaortic myectomy. Ann Thorac Surg. April 18, 2018 [Epub ahead of print].

11. Nguyen A, Schaff HV, Nishimura RA, Dearani JA, Geske JB, Lahr BD, et al. Does septal thickness influence outcome of myectomy for hypertrophic obstructive cardiomyopathy? Eur J Cardiothorac Surg. 2018;53:582-9.

12. Deb SJ, Schaff HV, Dearani JA, Nishimura RA, Ommen SR. Septal myectomy results in regression of left ventricular hypertrophy in patients with hypertrophic obstructive cardiomyopathy. Ann Thorac Surg. 2004;78:2118-22.

13. Maron BJ, Maron MS. Contemporary strategies for risk stratification and prevention of sudden death with the implantable defibrillator in hypertrophic cardiomyopathy. Heart Rhythm. 2016;13:1155-65. 